\title{
PKM KADER DESA PRAKTEK PIJAT PUNGGUNG PADA IBU NIFAS UNTUK MEMPERLANCAR ASI
}

\author{
Nurul Azizah'), Audrey Gracelia Riwu ${ }^{2}$ \\ Fakultas Kedoteran, Universitas Airlangga Surabaya \\ email: nurulazizah@umsida.ac.id ${ }^{1)}$, audrey.gracelia.riwu-2020@ fk.unair.ac.id ${ }^{2)}$
}

\begin{abstract}
Abstrak
Peran kader sangat penting untuk membantu sosialisasi kegiatan untuk meningkatkan status kesehatan masyarakat, pemerintah kabupaten Sidoarjo berkomitmen meningkatkan status gizi dan ASI eksklusif dengan menetapkan perda nomor 1 tahun 2016, diharapkan seluruh masyarakat mendukung perda tersebut. Di desa Sambibulu juga mendukung tercapainya Asi eksklusif, Kader Desa Durung Bedug Candi Sidoarjo aktif dalam kegiatan dimasyarakat untuk mendukung pembentukan UKBM (upaya kesehatan berbasis masyarakat) selain posyandu terbentuk juga kelompok pundukung ASI (KP ASI) untuk membantu tercapainya ASI eksklusif. Berdasarkan survey didapatkan hasil yakni cakupan ASI eksklusif masih rendah yakni 56\% dari target $80 \%$ dan salah satu penyebabnya yakni karena produksi ASI kurang. Kegitaan KP ASI yang sudah berjalan namun belum terdapat upaya untuk membantu meningkatkan produksi ASI.

Kader belum pernah mendapatkan pengetahuan tentang upaya untuk meningkatkan produksi ASI. Berdasarkan permasalahan maka tim pengusul memebrikan solusi dalam mengatasi kurangnya pengetahuan dan keterampilan kader tentang cara meningkatkan produksi ASI. dengan memberikan sebuah pelatihan dan pendampingan praktek pijat punggung pada kader untuk membantu meningkatkan produksi ASI.

Kader Desa Durung Bedug Candi Sidoarjo termasuk kader yang mempunyai loyalitas tinggi dan aktif, sehingga tim pengusul lebih mudah untuk memberikan pelatihan dan pendampingan tentang praktek pijat punggung untuk meningkatkan produksi ASI, yang nantinya diinformasikan kepada masyarakat sebagai upaya untuk meningkatkan produksi ASI dan masyarakat dapat melakukan pijat punggung secara mandiri.
\end{abstract}

Kata kunci : kader, pijat punggung

\begin{abstract}
Abstrack
The role of cadres is very important to help socialize activities to improve public health status, the Sidoarjo regency government is committed to improving nutritional status and exclusive breastfeeding by enacting regional regulation number 1 of 2016, it is hoped that the whole community will support this perda. In the village of Sambibulu also supports the achievement of exclusive Asi, the Village Cadre of Durung Bedug Candi Sidoarjo is active in community activities to support the formation of UKBM (community-based health efforts) in addition to posyandu a support group for ASI (KP ASI) is also formed to help achieve exclusive breastfeeding. Based on a survey conducted by the proposing team to cadres, it was found that exclusive breastfeeding coverage was still low, namely $56 \%$ of the $80 \%$ target and one of the reasons was due to insufficient breast milk production. The activities of KP ASI are already running but there have been no efforts to help increase milk production.

Cadres have never received knowledge about efforts to increase milk production. Based on these problems, the proposing team offered a solution to help overcome the cadres' lack of knowledge and skills in increasing breast milk production. One of the efforts offered by the team of proposers
\end{abstract}


was to provide training and practical assistance to back massage to cadres to help increase milk production.

Cadres of Desa Durung Bedug Candi Sidoarjo are among the cadres who have high loyalty and are active, so that it is easier for the proposing team to provide training and assistance on back massage practices to increase breast milk production, which will be informed to the community as an effort to increase milk production and people can do massage back independently.

Keyword : Cader, Back Massage 


\section{PENDAHULUAN}

ASI merupakan utrisi terbaik yang dibutuhkan dibutuhkan bayi, terutama pada 6 bulan pertama dalam kehidupannya (1). Pada tahun 2001 WHO menyatakan bahwa pemberian ASI secara eksklusif selama enam bulan pertama hidup bayi merupakan hal terbaik dalam pemenuhan nutrisi bayi (2). ASI ekslusif merupan ASI yang diberikan kepada bayi tanpa makanan dan minuman tambahan apapun mulai dari umur 0-6 bulan (3). Memberikan makanan selaian ASI pada bayai sebelum umur 6 bulan berisiko membahayakan kesehatan bayi (4).

Berdasarkan penelitian pemberian ASI Ekslusif di Indonesia masih masih cukup rendah (5). Risdaskes,2011 menyataka Bayi yang diberikan ASI Ekslusif hanya 15,3\%. Cakupan ASI yang rendah merupakan ancaman bagi tumbuh kembang anak yang dapat berpengaruh kualitas sumber daya manusia (6).

Pembentukan Kader Kesehatan bertujuan untuk mensukseskan pembangunan kesehatan secara nasional, sebagai upaya untuk meningkatkan derajat kesehatan masyarakat, peran aktif dan tanggung jawab kader sangat penting (7). Dalam hal ini peran kader sangat dibutuhkan dalam memberikan sosialisasi kepada masyarakat sebagai upaya meningkatkan status kesehatan ibu dan bayi. Oleh karena itu kader harus mempunyai pengetahuan dan keterampilan yang baik tentang kesehatan ibu dan anak, salah satunya adalah tentang pemberian nutrisi yang tepat untuk bayi yaitu ASI eksklusif.

Pemberian ASI eksklusif menjadi tanggung jawab seluruh masyarakat (8). Di Kabupaten Sidoarjo untuk meningkatkan status gizi dan ASI eksklusif diterbitkan perda nomor 1 tahun 2016. Seluruh lapisan masyarakat diharapkan mendukung perda tersebut, termasuk Desa Durung Bedug Candi Sidoarjo juga sangat mendukung ASI eksklusif. Kader merupakan orang yang terdekat dengan masyarakat (9), sehingga kader mempunyai peranan penting dalam mewujudkan keberhasilan program peningkatan status gizi dan ASI eksklusif.

Kader Desa Durung Bedug Candi Sidoarjo berjumlah 21 kader dengan latar belakang pendidikan sebagian besar SMP, yang berusia diatas 35 tahun, dan telah aktif menjadi kader lebih dari 5 tahun. Seluruh kader Desa Durung Bedug Candi Sidoarjo mempunyai loyalitas tinggi dan aktif dalam setiap kegiatan yang diadakan. Kader membantu bidan desa untuk meningkatkan derajat kesehatan masyarakat termasuk pemberian ASI eksklusif. Untuk menunjang kegiatan tersebut, desa memberikan fasilitas yang menunjang kegiatan yang dilakukan oleh kader berupa; posyandu yang terdiri dari 5 pos yang dilengkapi dengan meja, kursi, timbangan, dan sarana administratif, serta ruang kelompok pendukung ASI (KP ASI).

Kegiatan yang dilakukan oleh kader meliputi ; membantu pelaksanaan posyandu dan pos bindu (pos pembinaan terpadu) (9). Kegiatan posyandu dilakukan setiap bulan pada masingmasing pos, selain kegiatan posyandu terdapat pertemuan rutin seluruh kader Desa Durung Bedug Candi Sidoarjo setiap bulan, dan bagi koordinator kader desa dilakukan pembinaan kader oleh petugas puskesmas setiap tiga bulan.

Kegiatan pertemuan kader setiap tiga berupa pembinaan, sosialisasi dan update program terbaru tentang kesehatan ibu dan anak (KIA), kemudian informasi yang diperoleh dari kegiatan tersebut akan disampaikan pada seluruh kader yang dilaksanakan pada pertemuan setiap bulan, selain itu petemuan bulanan juga membahas pelaksanaan dan hambatan dari kegiatan yang telah dilakukan oleh kader pada tiap pos.

Kader Desa Durung Bedug Candi Sidoarjo juga aktif dalam mendukung pembentukan UKBM (upaya kesehatan berbasis masyarakat) 
selain posyandu yaitu terbentuk juga kelompok pundukung ASI (KP ASI) untuk membantu tercapainya ASI eksklusif. Kegiatan KP ASI oleh kader antara lain pemberian materi tentang asi eksklusif dan kader juga memfasilitasidiskusi antar anggota KP ASI sehingga ASI eksklusif dapat diterapkan oleh masyarakat desa Desa Durung Bedug Candi Sidoarjo.

Berdasarkan survey pada kader didapatkan hasil bahwa cakupan ASI eksklusif masih rendah yakni 56\% dari target $80 \%$ dan salah satu penyebabnya yakni karena produksi ASI kurang. Pada kegitaan KP ASI yang sudah berjalan belum terdapat upaya untuk membantu meningkatkan produksi ASI.

Berdasarkan permasalahan kurangnya pengetahuan dan keterampilan kader dalam meningkatkan produksi ASI, maka solusinya dengan memberikan sebuah pelatihan dan pendampingan praktek pijat punggung pada kader untuk membantu meningkatkan produksi ASI. Kader desa Durung Bedug termasuk kader yang mempunyai loyalitas tinggi dan aktif, sehingga tim pengusul lebih mudah untuk memberikan pelatihan dan pendampingan tentang praktek pijat punggung untuk meningkatkan produksi ASI, yang nantinya diinformasikan kepada masyarakat sebagai upaya untuk meningkatkan produksi ASI dan masyarakat dapat melakukan pijat punggung secara mandiri.

\section{METODE PELAKSANAAN}

Kegiatan ini dimulai dengan melakukan survei untuk melihat dan menganalisis situasi, kemudian melakukan pendekatan dan meminta persetujuan terhadap untuk pelatihan dan penyuluhan tentang PKM Kader Desa Sambibulu Praktek Pijat Punggung pada Ibu Nifas untuk Memperlancar ASI. Kegiatan dilakukan dengan metode ceramah melalui penyuluhan dan pelatihan sebagai berikut : a. Meningkatkan pengetahuan kader tentang cara meningkatkan produksi ASI. Mitra belum pernah mendapatkan pengetahuan dan katerampilan praktik pijat punggung untuk meningkatkan produksi ASI. Menurut sebuah penelitian yang dilakukan oleh vidayanti 2015 menyatakan bahwa dengan memijat punggung pada titik costa 5 dan 4 dapat menstimulasi hormon oksitosin untuk mengeluarkan produksi ASI (10) melaui workshop dan pelatihan ini akan diberikan suatu informasi melalui seminar pijat punggung untuk meningkatkan produksi ASI.

b. Mengadakan pelatihan untuk meningkatkan keterampilan kader. Dengan adnya pengetahuan yang baik maka akader dapat menyampaiakan informasi dengan baik (11). Selama ini kader belum pernah mendapatkan pelatihan mengenai praktik pijat punggung, sehingga kader memiliki kemampuan dan keterampilan pijat punggung yang nantinya dapat sampaikan kepada masyarakat agar mempu melaksanakan pijat punggung secara mandiri, sehingga produksi ASI dapat meningkat dan kebutuhan nutrisi bayi terpenuhi

\section{HASIL DAN PEMBAHASAN}

a. Workshop penyuluhan tentang kesehatan remaja telah dilaksanakan pada tanggal 8 Agustus 2020 melalui webinar yang dilakukan pasa seluruh kader kesehatan Durung Bedug Candi Sidoarjo, hasil yang di dapatkan para kader dapat memahami tentang caracara agas asi ibu nifas bisa lancar dan produksi ASI banyak, para santri mendapatkan pengetahuan baru sehingga kedepan dapat disampaikan kepada masyarat yang menjalani masa nifas, yang datang pasa saat posyandu di akhir penyuluhan terdapat beberapa kader yang mengajukan pertanyaan, serta menjawab saat presentator 
memberikan review dari materi yang telah disampaikan.

b. Workshop dan pelatihan praktik pijat punggung kepada kader kesehatan desa durung bedug telah dilaksanakan pada tanggal 8 Agustus 2020 melalui webinar, hasil menunjukkan para kader dapat memahami dan mempraktekkan kembali cara melakukan pijat punggung untuk memperlancar produksi ASI pada ibu menyusui dengan baik. Para kader mengikuti acara dengan antusias hingga selesai, serta terdapat beberapa kader mengajukan pertanyaan esulitan praktik, serta menjawab pertanyaan saat presentator memberikan review dari materi yang telah disampaikan.

\section{KESIMPULAN}

Kegiatan Program pengabdian masyarakat ini telah dilaksanakan, para kader kesehatan desa durung bedug candi sidoarjo telah mendapatkan pengetahuan baru cara praktek pijat punggung untuk memperlancar produksi ASI.

\section{REFERENSI}

1. Astuti I. Determinan Pemberian ASI Eksklusif Pada Ibu Menyusui. Heal Qual. 2013;

2. Sudirman \& Supriayaty. Manajemen Laktasi Terhadap Keberhasilan Pemberian ASI Ekslusif. J Kesehat Masy. 2018;

3. Nilakesuma A. Hubungan Status Gizi Bayi dengan Pemberian ASI Ekslusif. J Kesehat. 2015;

4. Mubarokah AZ, Muniroh L. The Effect Of Socio-Culture Of Nutrition On Exclusive Breastfeeding Of Maduranese In Bangkalan Public Health Center, Madura. Amerta Nutr. 2020;

5. Widodo Y. Cakupan Pemberian Asi Eksklusif: Akurasi Dan Interpretasi Data Survei Dan Laporan Program. Gizi Indones. 2014;

6. Langkah Peningkatan Pemberian ASI Eksklusif di Kabupaten Semarang. J Promosi Kesehat Indones. 2018;

7. Tse ADP, Suprojo A, Adiwidjaja I. Peran Kader Posyandu Terhadap Pembangunan
Kesehatan Masyarakat. J Ilmu Sos dan Ilmu Polit Univ Tribhuwana Tunggadewi. 2017;

8. Danefi T. Promosi Kesehatan Dalam Peningkatan Perilaku Pemberian Asi Eksklusif Di Desa Singasari Kecamatan Singaparna Kabupaten Tasikmalaya Tahun 2020. J ABDIMAS Kesehat TASIKMALAYA. 2020;

9. Susanto F, Claramita M, Handayani S. Peran kader posyandu dalam memberdayakan masyarakat Bintan. Ber Kedokt Masy. 2017;

10. Vidayanti V. Pengaruh Pijat Punggung Menggunakan Minyak Esensial Lavender Terhadap Produksi ASI Pasca Bedah Sesar di RSUD Panembahan Senopati bantul. J Med Respati. 2015;

11. Purwati Y, Salmiyati S, Imallah RN. Pendampingan Kader Kesehatan Dalam Strategi Produksi Dan Promosi Mp-Asi. Abdimas Dewantara. 2018;

12. Nuraini, I., Ningrum, N. P., \& Iswati, R. S. (2019). Pengaruh Menyusui Secara Eksklusif Terhadap Involusi Uteri Pada Ibu Nifas Di Bpm Yefi Marliandiani Rungkut Surabaya Tahun 2018. Jurnal Kebidanan Indonesia: Journal of Indonesia Midwifery, 10(1), 49-55. 